\title{
IGovP: índice de avaliação da governança pública - instrumento de planejamento do Estado e de controle social pelo cidadão
}

\author{
Antonio Gonçalves de Oliveira \\ Universidade Tecnológica Federal do Paraná / Departamento Acadêmico de Gestão e \\ Economia, Programa de Pós-Graduação em Planejamento e Governança Pública \\ Curitiba / PR - Brasil \\ Beatriz Jackiu Pisa \\ Universidade Tecnológica Federal do Paraná / Departamento Acadêmico de Gestão e \\ Economia, Programa de Pós-Graduação em Planejamento e Governança Pública \\ Curitiba / PR - Brasil
}

\begin{abstract}
O conceito de governança pública envolve, entre outros aspectos da gestão, transparência, prestação de contas (accountability), ética, integridade, legalidade e participação social nas decisões. Mas como avaliar o grau com que cada ente federativo se esforça por cumprir os princípios da governança pública na implementação de suas políticas públicas? Em resposta a essa questão, o objetivo deste estudo é desenvolver um índice de medição da governança pública e fazer isso a partir do ponto de vista de seus princípios, bem como apresentá-lo como um instrumento de autoavaliação e planejamento para o Estado e de controle social para os cidadãos. Metodologicamente, o trabalho tem caráter aplicado, sustentado por pesquisa exploratória e descritiva, com abordagem finalística comparada. Como resultado, o índice desenvolvido é apresentado, comprovando-se sua aplicabilidade e finalidades pressupostas.
\end{abstract}

Palavras-chave: governança pública; avaliação; indicadores; controle social; efetividade das políticas públicas.

IGovP: índice de evaluación de la gestión pública — un instrumento de planificación del Estado y control social por parte del ciudadano

El concepto de gobernanza pública implica, entre otros aspectos de la gestión, la transparencia, la rendición de cuentas (accountability), la ética, la integridad, la legalidad y la participación social en las decisiones. Pero cómo evaluar el grado en que cada entidad federativa se esfuerza por cumplir con los principios de la gobernanza pública en la implementación de las políticas públicas? En respuesta a esto, el objetivo de este estudio es desarrollar un índice para medir la gobernanza pública y de hacerlo

DOI: http://dx.doi.org/10.1590/0034-7612136179

Artigo recebido em 10 jun. 2014 e aceito em 30 abr. 2015. 
desde el punto de vista de sus principios y presentarlo como una herramienta de auto-evaluación y la planificación de lo Estado y de control social de los ciudadanos. El estudio es práctico, con el apoyo de la investigación exploratoria y descriptiva, con enfoque comparativo. Como resultado, se presenta el índice desarrollado, lo que confirma su aplicabilidad y propósitos asumidos.

Palabras clave: gobernanza pública; evaluación; indicadores; control social; efectividad de las políticas públicas.

IGovP: the public governance assessment index — a State planning instrument tool and social control by the citizen

The concept of public governance involves, among other aspects of management, transparency, accountability, ethics, integrity, legality and social participation in decisions. But how to evaluate the degree to which each federative entity strives to fulfill the principles of public governance in the implementation of public policies? Answering this question, the aim of this study is to develop an index to measure the public governance and to do so from the point of view of its principles, and present it as a tool for self-evaluation and planning for the State and control social for the citizens. Methodological work has applied character, supported by exploratory and descriptive research, with a comparative approach. As a result, the index developed is presented and confirms its applicability and assumed purposes.

KEYWoRDs: public governance; assessment; indicators; social control; public policies' effectiveness.

\section{Introdução}

A Constituição Federal de 1988 é conhecida como Constituição Cidadã por conceder aos brasileiros direitos inéditos, próprios do estado democrático de direito que se implantou a partir de então, entre eles o de exercer o controle sobre a administração pública, de exigir ética, integridade (compliance), transparência (disclosure) e prestação de contas (accountability), bem como de participar diretamente na escolha das políticas públicas a serem implantadas.

Nesse contexto, a partir dos anos 1990 observa-se uma reestruturação do Estado, com o intuito de torná-lo mais orientado para os aspectos sociais, visando consolidar uma "nova" relação entre Estado e sociedade.

A partir dessa nova relação estabelecida, evolui-se então para a noção de governança, que se refere à capacidade do Estado de implementar as políticas necessárias para o alcance dos objetivos comuns e pressupõe o aperfeiçoamento dos meios de interlocução com a sociedade, ao passo que sejam promovidas ações que garantam a maior atuação do cidadão e responsabilização dos agentes públicos.

Na verdade, ainda faltam instrumentos avaliativos que exponham de forma sistemática e tempestiva a efetividade das ações governamentais e que tenham por base os princípios da governança pública aplicados à materialização das políticas públicas, sejam elas de Estado ou de governo.

Políticas públicas devem ser compreendidas como aquelas ações que um determinado governo escolhe implementar com o objetivo de atender a uma demanda pública ou resolver 
um problema, lembrando-se que essa escolha sofre forte influência política em função dos interesses dos diversos setores que podem por ela ser beneficiados.

A utilização de modelos de análise e mensuração detalhada por indicadores que tenham como substrato os princípios da governança pública representa uma inovação no sentido de ser um mecanismo eficaz de conhecimento do grau de governança praticada pela União, Distrito Federal e estados, permitindo-se, inclusive, o acompanhamento de sua evolução.

Considere-se que, para mensurar o nível de governança, devem-se relacionar seus princípios com as ações resultantes de suas aplicações. Isso implica a existência e disponibilização de dados históricos da evolução de indicadores sociais relacionados com a implementação de políticas públicas.

É importante esclarecer que inúmeras organizações internacionais têm desenvolvido indicadores e publicado estudos sobre a mensuração da governança, como a Organização para a Cooperação e Desenvolvimento Econômico (Ocde); o Banco Mundial; o Programa das Nações Unidas para o Desenvolvimento (Pnud); o International Country Risk Guide. Porém, esses estudos, na visão de Van de Walle (2005), ilustram situação de comparação entre diversos países de forma genérica e subjetiva, não contemplando a realidade e as particularidades de cada um. No entanto, eles são úteis como fontes de informação e metodologia de avaliação.

Oman e Arndt (2010) alertam que tais indicadores são baseados em percepções e, ainda que cuidadosamente construídos, são eivados de limitações por agregar grandes quantidades de informações de diversas fontes e reduzi-las a um único número - um único escore de governança - por país, por ano, a fim de facilitar comparações.

Essas informações agregadas consistem em percepções de pessoas, em sua maioria especialistas ou gestores de empresas, muitos dos quais vivem fora dos países que estão sendo analisados (Oman e Arndt, 2010:4).

No Brasil, existem poucos estudos cujo enfoque relaciona a governança ao uso das tecnologias de informação e comunicação (TICs) e da internet. Nesse contexto, insere-se a noção de governança eletrônica, cuja estrutura conceitual tem um de seus fundamentos no trabalho de Holzer e Kim (2006), os quais consideram que a governança eletrônica inclui o governo eletrônico (prestação de serviços públicos) e a democracia eletrônica (participação cidadã no governo).

No entanto, não foram encontrados estudos no âmbito da governança eletrônica, específicos sobre o desenvolvimento de um índice de governança pública aplicado aos entes federativos com objetivo de avaliar a efetividade das políticas públicas.

Com a constatação da falta de uma ferramenta específica de medição e o interesse de contribuir para sua criação, apresenta-se este estudo cuja inquietude busca resposta à seguinte questão de pesquisa: é possível a criação de um índice consistente, atrelado aos princípios da governança pública, capaz de avaliar o grau de governança praticado pelos entes federativos?

É exatamente essa a proposta deste artigo: comprovar a possibilidade de desenvolvimento de um índice de avaliação da governança pública, inédito no Brasil, e fazer isso a partir do ponto de vista de seus princípios, bem como apresentá-lo como um instrumento de autoavaliação para o Estado e de controle social para os cidadãos. 
Para cumprir sua proposta, o trabalho divide-se em quatro partes, sendo esta introdução a primeira; e a segunda, aquela em que se fundamenta teoricamente o estudo, abordando os conceitos de governança pública; controle social; avaliação da governança; índices e indicadores.

Na terceira parte apresentam-se os procedimentos metodológicos, na qual se detalham os instrumentos, critérios e procedimentos adotados e se ilustra o quadro conceitual e de formação metodológica dos indicadores selecionados para a formação do Índice de Avaliação da Governança Pública (IGovP).

A quarta parte traz os resultados, comprovando a aplicabilidade do modelo e apresentando os resultados, inclusive com o estabelecimento, a título de ilustração, de um ranking do grau de governança dos estados, Distrito Federal e União, e outro ranking, com o valor atribuído às grandes regiões geográficas do país.

\section{Fundamentação teórica}

\subsection{Governança e principiologia: da corporativa à pública}

Para os fins aqui propostos, esta seção se dedica à abordagem teórica da governança corporativa, suas definições, aplicações e princípios, que são fundamentais para os fins deste estudo, versando sobre sua utilização nos diversos entes organizacionais e em especial no âmbito da esfera pública.

O tema da governança corporativa ganhou projeção a partir da década de 1980, em função da pressão de fundos de pensão norte-americanos que cobravam das companhias mais transparência e informações, buscando limitar os abusos dos controladores (Souza, 2005).

No entanto, ao se aprofundar na história, observa-se que o assunto governança corporativa já se fazia presente em trabalhos datados de 1932, como os de Berle e Means, que tratavam da separação entre controle e gestão, os quais, segundo apontamentos de Borges e Serrão (2005:114), colocam a problemática da teoria da agência, como a "contradição existente na relação bilateral estabelecida quando o bem-estar de uma parte (o proprietário ou principal) depende de decisões tomadas por outra parte (o agente)", como o marco inicial em governança corporativa.

Decorrente da assimetria informacional entre agente e principal focalizada pela teoria da agência, tornou-se imprescindível a adoção dos princípios da governança corporativa, principalmente, a partir dos escândalos financeiros relacionados com fraudes contábeis e expropriação da riqueza dos acionistas por parte dos executivos, os quais tiveram início no setor energético, estendendo-se em seguida a inúmeras corporações norte-americanas (Borges e Serrão, 2005:112; Andrade e Rossetti, 2009:89).

No Brasil, o tema governança corporativa ganha importância a partir dos anos 1990, após a falência de companhias abertas e do fechamento de grandes bancos privados pelo Banco Central, trazendo a público inúmeros esquemas de fraude nos registros e padrões contá- 
beis. Esses fatos puseram em xeque a confiança nas auditorias independentes e incentivaram a busca por melhorar os níveis de governança corporativa (Borges e Serrão, 2005:121).

No quadro 1 ilustram-se algumas das definições de governança, ressaltando que não existe definição unânime, uma vez que o conceito de governança evoluiu no tempo e adaptouse às diferentes sociedades e culturas onde foi adotado.

Quadro 1

\section{Definições de governança corporativa}

\begin{tabular}{|c|c|c|}
\hline Ano & Autor/Entidade & Definição de Governança Corporativa \\
\hline 1992 & Cadbury Committee & $\begin{array}{l}\text { O conjunto de todos os sistemas de controle, tanto financeiros como outros, pelos quais } \\
\text { uma firma é dirigida e controlada. }\end{array}$ \\
\hline 2001 & Jensen & $\begin{array}{l}\text { Governança é a estrutura de controle de alto nível, consistindo dos direitos de decisão do Con- } \\
\text { selho de Administração e do diretor executivo, dos procedimentos para alterá-los, do tamanho e } \\
\text { composição do Conselho de Administração e da compensação e posse de ações dos gestores } \\
\text { e conselheiros. }\end{array}$ \\
\hline 2002 & CVM & $\begin{array}{l}\text { Governança corporativa é o conjunto de práticas que tem por finalidade otimizar o desem- } \\
\text { penho de uma companhia ao proteger todas as partes interessadas, tais como investidores, } \\
\text { empregados e credores, facilitando o acesso ao capital. }\end{array}$ \\
\hline 2004 & Ocde & $\begin{array}{l}\text { Relações entre a administração da sociedade, seu conselho, acionistas e outras partes interes- } \\
\text { sadas. A governança corporativa proporciona a estrutura que possibilitará o estabelecimento } \\
\text { dos objetivos da sociedade, bem como os meios de cumpri-los e supenvisionar o desempenho } \\
\text { da sociedade. }\end{array}$ \\
\hline 2009 & IBGC & $\begin{array}{l}\text { Governança corporativa é o sistema pelo qual as organizações são dirigidas, monitoradas } \\
\text { e incentivadas, envolvendo os relacionamentos entre proprietários, Conselho de } \\
\text { Administração, Diretoria e órgãos de controle. As boas práticas de governança corporativa } \\
\text { convertem princípios em recomendações objetivas, alinhando interesses com a finalidade } \\
\text { de preservar e otimizar o valor da organização, facilitando seu acesso a recursos e } \\
\text { contribuindo para sua longevidade. }\end{array}$ \\
\hline
\end{tabular}

Fonte: Elaboração dos autores a partir do autor e entidades referenciadas.

As boas práticas de governança corporativa convertem princípios em recomendações objetivas, alinhando interesses com a finalidade de preservar e aumentar o valor da organização, facilitando seu acesso a recursos e contribuindo para sua longevidade (IBGC, 2009).

Para uma melhor compreensão acerca da temática, o quadro 2 apresenta alguns desses arranjos principiológicos (Andrade e Rosseti, 2004; IBGC, 2009), em que se observam ideias convergentes em pontos específicos, como transparência, ética, equidade, obediência às leis e regulamento, bem como a obrigação de prestar contas. 


\section{Princípios de governança corporativa e suas finalidades}

\begin{tabular}{|c|c|c|}
\hline Autor/Entidade & Princípios & Finalidades \\
\hline \multirow{4}{*}{$\begin{array}{l}\text { Andrade e Rossetti } \\
\text { (2004) }\end{array}$} & Accountability & $\begin{array}{l}\text { Responsabilidade por prestar contas, fundamentada nas melhores práticas } \\
\text { contábeis e de auditoria. }\end{array}$ \\
\hline & Compliance & $\begin{array}{l}\text { Conformidade legal e cumprimento de normas reguladoras contidas nos } \\
\text { estatutos sociais, nos regimes internos e nas instituições do país. }\end{array}$ \\
\hline & Disclosure & $\begin{array}{l}\text { Consiste na transparência e lisura na divulgação de dados e relatórios } \\
\text { contábeis. }\end{array}$ \\
\hline & Fairness & $\begin{array}{l}\text { Equidade é o senso de justiça para com todos os acionistas, } \\
\text { independentemente de serem majoritários ou não, e também com os } \\
\text { demais stakeholders. }\end{array}$ \\
\hline \multirow{4}{*}{ IBGC (2009) } & Transparência & $\begin{array}{l}\text { Mais do que a obrigação legal de informar, importante é criar a cultura de } \\
\text { disponibilizar as informações às partes interessadas. } \\
\text { A transparência resulta da confiança, tanto internamente quanto nas } \\
\text { relações da empresa com terceiros. } \\
\text { Não deve ser restrita ao desempenho econômico-financeiro, contemplando } \\
\text { inclusive os demais fatores (mesmo os intangíveis) que orientam a ação } \\
\text { gerencial e criam valor para a empresa. }\end{array}$ \\
\hline & Equidade & $\begin{array}{l}\text { Caracteriza-se pelo tratamento justo de todos os sócios e demais } \\
\text { stakeholders. } \\
\text { São consideradas inaceitáveis quaisquer atitudes ou políticas } \\
\text { discriminatórias. }\end{array}$ \\
\hline & $\begin{array}{l}\text { Prestação de Contas } \\
\text { (accountability) }\end{array}$ & $\begin{array}{l}\text { Os agentes de governança devem prestar contas de sua atuação, } \\
\text { assumindo integralmente as consequências de seus atos e omissões. }\end{array}$ \\
\hline & $\begin{array}{l}\text { Responsabilidade } \\
\text { Corporativa }\end{array}$ & $\begin{array}{l}\text { Os agentes de governança devem zelar pela sustentabilidade das } \\
\text { organizações, incorporando a responsabilidade social e ambiental na } \\
\text { condução dos negócios e operações. }\end{array}$ \\
\hline
\end{tabular}

Fonte: Elaboração dos autores a partir de Andrade e Rossetti (2004:23); IBGC (2009:19).

As práticas da gestão privada repercutiram favoravelmente em outros setores, contribuindo para a discussão do tema da governança no setor público. No entender de Kissler e Heidemann (2006:480), a repercussão do tema ocorreu devido às condições insatisfatórias dos modelos adotados até então, que, para Paes de Paula (2005), privilegiavam a eficiência e qualidade da gestão, sem abertura do mesmo espaço para atendimento às questões sociais, ao mesmo tempo que restringiam a participação do cidadão nos processos decisórios.

Encaminhando a discussão para a efetividade na área pública, concernente ao entendimento sobre a "boa governança no setor público", o Ifac (2001) enfatiza que é função da governança garantir a supremacia do interesse público em todos os momentos. 
Para ilustrar a amplitude das definições institucionais de governança pública, o quadro 3 contempla algumas das entidades que lhe dedicaram atenção:

Quadro 3

Definições de governança pública por organizações nacionais e estrangeiras

\begin{tabular}{|c|c|c|}
\hline Ano & Organização & Definição de Governança Pública \\
\hline 2006 & Ocde & $\begin{array}{l}\text { A governança diz respeito aos arranjos formais e informais que determinam como são to- } \\
\text { madas as decisões públicas e como são implementadas as ações públicas, na perspectiva } \\
\text { de manter os valores constitucionais de um país em face de vários problemas, atores e } \\
\text { ambientes. }\end{array}$ \\
\hline 2011 & $\begin{array}{l}\text { Tribunal de } \\
\text { Contas da União } \\
\text { (TCU) }\end{array}$ & $\begin{array}{l}\text { (...) governança pública constitui um instrumento cujo objetivo é assegurar a accountability } \\
\text { pública, contribuindo para reduzir as incertezas sobre o que ocorre no interior da administração } \\
\text { pública, fornecendo à sociedade e ao Congresso Nacional uma razoável segurança de que os } \\
\text { recursos e poderes delegados aos administradores públicos estão sendo geridos mediante } \\
\text { ações e estratégias adequadas para alcançar os objetivos estabelecidos pelo poder público, } \\
\text { de modo transparente, em conformidade com os princípios de administração pública, as leis } \\
\text { e os regulamentos aplicáveis. }\end{array}$ \\
\hline 2013 & World Bank & $\begin{array}{l}\text { Governança é o conjunto das tradições e instituições pelas quais a autoridade de um país é } \\
\text { exercida. Isso inclui o processo pelo qual os governos são selecionados, monitorados e substi- } \\
\text { tuídos, a capacidade do governo de formular e implementar políticas sólidas de forma eficaz, e } \\
\text { o respeito dos cidadãos e do Estado pelas instituições que governam as interações econômicas } \\
\text { e sociais entre eles. }\end{array}$ \\
\hline
\end{tabular}

Fonte: Elaboração dos autores a partir dos conceitos emitidos pelas entidades referenciadas.

Entre autores brasileiros, destacam-se as definições de governança pública de Bresser-Pereira (1998:33) como "a capacidade financeira e gerencial de formular e implementar políticas públicas". E também o entendimento de Matias-Pereira (2010:124) de que, para existir a boa governança, deve estar presente o fator "participação proativa de todos os atores envolvidos: dirigentes, políticos, órgãos de controle e, em especial, da sociedade organizada".

Não obstante o amplo espectro acerca da temática, no interesse de delimitar os princípios da governança pública para aferição por meio de indicadores, objeto deste estudo, adotam-se os seguintes princípios: 1. Efetividade 2. Transparência; 3. Accountability; 4. Participação; 5. Equidade; 6. Conformidade Legal; 7. Integridade/Ética.

Sobre a efetividade, esta diz respeito à averiguação da real necessidade e oportunidade de determinadas ações governamentais e refere-se aos impactos por ela gerados. Nesse sentido, "a efetividade está vinculada ao grau de satisfação ou, ainda, ao valor agregado" (Martins e Marini, 2010:79).

Quanto à transparência, o Relatório da Ocde (2011:3) expressa que, no exercício da governança, "o Estado deve ser transparente o suficiente na apresentação dos dados, para que se possa avaliar se os investimentos estão sendo realizados de maneira eficaz, eficiente e efetiva, com a lisura que se espera do gestor público". 
Merece destaque a importância de que não se deve confundir o princípio da transparência com publicidade, conforme alertam Platt Neto e colaboradores (2007:75), uma vez que, além da publicidade, o princípio da transparência pressupõe a compreensibilidade das informações e a utilidade para subsidiar decisões.

Pinho e Sacramento (2009:1349) analisam o conceito de accountability como uma via de mão dupla do termo - a primeira supõe a responsividade como a obrigação de informar e justificar; a outra mão consiste na noção de responsividade como answerability, que significa responsabilização com possibilidade de sanção (enforcement), em função da violação no cumprimento do dever.

Accountability é então definido como "um atributo do Estado, enquanto controle social é um atributo ou qualidade da própria sociedade civil, que deve ser municiada e habilitada para acionar os mecanismos de interpelação junto à gestão pública" (Ferreira, 2006:23).

A participação dos cidadãos se dá principalmente pela participação nas eleições para escolha dos representantes do povo no âmbito dos entes federados. Outras possibilidades ocorrem pela participação nas organizações da sociedade civil (orçamentos participativos, conselhos de programas e políticas públicas), que contribuem para o estreitamento da relação entre o Estado e a sociedade.

A mudança rumo "a um Estado mais eficaz e disposto a discutir e responder aos anseios da sociedade certamente perpassa pela existência de uma cidadania mais ativa e engajada na busca de soluções" (Spink, 2012:365).

Concernente ao Compliance, esse é um termo anglo-saxão que significa conduta de acordo com a regra. Na visão de Manzi (2008:123), o Brasil procura consolidar a compliance como uma das bases da governança ao implantar meios para assegurar a conformidade com normas, leis e políticas internas e externas, ao passo que fortalece a cultura do ambiente ético por meio de controles internos e aumento da transparência.

Quanto ao princípio da legalidade, linha mestra das ações praticadas no âmbito do setor público, ele é positivado na Constituição Federal, art. 5o, inciso II, comando imperativo de que: "Ninguém será obrigado a fazer ou deixar de fazer alguma coisa senão em virtude de lei" (Brasil, 1988). Lembrando que, em se tratando do setor público, tem-se ainda a positivação da legalidade no caput do art. 37 da mesma Carta Republicana, cujo cumprimento restringe as ações dos gestores públicos somente ao que está expressamente previsto em lei.

Conforme o posicionamento de Ferraz Júnior (2009), o princípio da legalidade diz respeito ao cumprimento das leis e dos regulamentos prescritos para a administração pública; e mais, além de cumprir o princípio da legalidade, o gestor deve fazê-lo com eficiência e eficácia, atendendo ao interesse público, ou seja, com efetividade.

E a equidade? De acordo com o Relatório sobre o Desenvolvimento Mundial 2006, ela resulta de dois princípios básicos: o primeiro é o princípio de oportunidades iguais: as conquistas individuais devem ser determinadas por seus talentos e esforços, e não por outras características como etnia, gênero, história social ou familiar ou, ainda, país de nascimento. O segundo princípio é o da prevenção de privação de resultados, especialmente em saúde, educação e níveis de consumo (Banco Mundial, 2006:9). 


\section{Justificativa e relevância do tema/estudo}

Muito mais do que o poder-dever de agir inerente aos gestores públicos, há que se fazê-lo fundamentado nos princípios constitucionais aplicados à administração pública e naqueles que envolvem a governança aplicada ao setor público, o que, obviamente, carece de avaliação para mensuração de sua efetividade.

Nesse sentido, Cohen e Franco (2007:77) definem a avaliação como "atividade que tem como objetivo maximizar a eficácia dos programas na obtenção de seus fins e a eficiência na alocação de recursos para a consecução dos mesmos".

No que concerne aos critérios de avaliação de políticas implementadas por determinado governo, Höfling (2001:30-31) argumenta que fatores de diferentes natureza e determinação influenciam e devem ser levados em conta, especialmente quando o objeto de análise são as políticas sociais.

Neste estudo é privilegiado o aspecto da efetividade quanto ao desenvolvimento social decorrente das ações governamentais ao concretizar as políticas públicas, pois ao atribuir graus de governança aos resultados observados faz-se possível apontar fatores a serem trabalhados com objetivo de redução de diferenças e desigualdades.

Para desenvolver indicadores de governança é importante levar em conta alguns critérios de análise, como:

a) O impacto social das ações governamentais em relação às expectativas dos cidadãos, que vão muito além do controle administrativo ou interesses instrumentais da Administração;

b) A eficiência, na medida em que as políticas reflitam o adequado retorno social em função da utilização de recursos escassos;

c) A transparência, que permita uma prestação de contas efetiva da autoridade pública, em termos de acesso e qualidade das informações disponibilizadas;

d) O respeito pela diversidade e inclusão social e igualdade para os grupos desfavorecidos;

e) Confiabilidade dos dados, que evidenciem uma relação observável entre as políticas avaliadas e os resultados observáveis;

f) O tratamento justo e imparcial dos cidadãos e o respeito pela legalidade e inclusão social; tomada de decisões democrática e cidadã e engajamento das partes interessadas;

g) Política de sustentabilidade. (Longo, 2011:6)

Em síntese, a partir desta revisão teórica acredita-se ter fundamentado as definições e conceitos necessários à resolução do problema de pesquisa e aos objetivos deste estudo.

\section{Metodologia}

Neste tópico são tratados os procedimentos metodológicos utilizados na criação do Índice de Avaliação da Governança Pública (IGovP) em função da observância aos princípios de governança selecionados na fundamentação teórica. 
Positivamente, o trabalho é de caráter aplicado, desenvolvido a partir de pesquisa exploratória e descritiva, com abordagem finalística comparada, fundamentado na pesquisa de ordem bibliográfica e documental.

\subsection{Considerações e critérios de formação dos indicadores do IGovP}

Registre-se que uma metodologia de avaliação requer o desenvolvimento de um arcabouço de critérios e a seleção de indicadores a eles relacionados, de tal forma consistentes que conduzam a uma aferição dos resultados com base nos padrões de referência preestabelecidos.

A aplicação de critérios exige formas específicas de operacionalização, já que constituem medidas indiretas, ou seja, devem ser calculadas a partir da identificação e quantificação dos resultados obtidos. Em geral, denomina-se essa outra categoria de medidas de indicadores.

Vale apresentar uma breve explanação sobre o que são indicadores e o que são índices. Nesse sentido, o IGovP é um índice composto por cinco indicadores que são agregados segundo critérios predeterminados, os quais, neste estudo, estão relacionados aos princípios de governança pública.

Assim, valoriza-se o entendimento sobre o que são indicadores, definido pelo Guia Metodológico do Ministério do Planejamento, Orçamento e Gestão (MPOG), no sentido de que:

Do ponto de vista de políticas públicas, os indicadores são instrumentos que permitem identificar e medir aspectos relacionados a um determinado conceito, fenômeno, problema ou resultado de uma intervenção na realidade. A principal finalidade de um indicador é traduzir, de forma mensurável, determinado aspecto de uma realidade dada (situação social) ou construída (ação de governo), de maneira a tornar operacional a sua observação e avaliação. (Brasil, 2010:23)

Na mesma discussão o MPOG reforça seu entendimento acerca do que vem a ser "índice" (ou indicador sintético):

Os índices ou indicadores sintéticos sintetizam diferentes conceitos da realidade empírica, ou seja, derivam de operações realizadas com indicadores analíticos e tendem a retratar o comportamento médio das dimensões consideradas. Diversas instituições nacionais e internacionais divulgam indicadores sintéticos, sendo exemplos o PIB, IDEB, IPC e o IDH. (Brasil, 2010:29)

A noção do conceito de índice e indicador pode ser mais bem avaliada pela observação do diagrama ilustrativo da formação de índices e indicadores, a seguir.

Quanto à formação do Índice de Avaliação da Governança Pública (IGovP), sua periodicidade é anual, sendo o Censo do Instituto Brasileiro de Geografia e Estatística (IBGE) uma das principais fontes de dados - que, apesar de decenal, prevê estimativas anuais. Porém, como inúmeras outras fontes oficiais de pesquisa estão fundamentadas no último censo, optou-se por utilizar os dados do ano de 2010 neste primeiro levantamento. 
Figura 1

Diagrama ilustrativo da formação de índices e indicadores

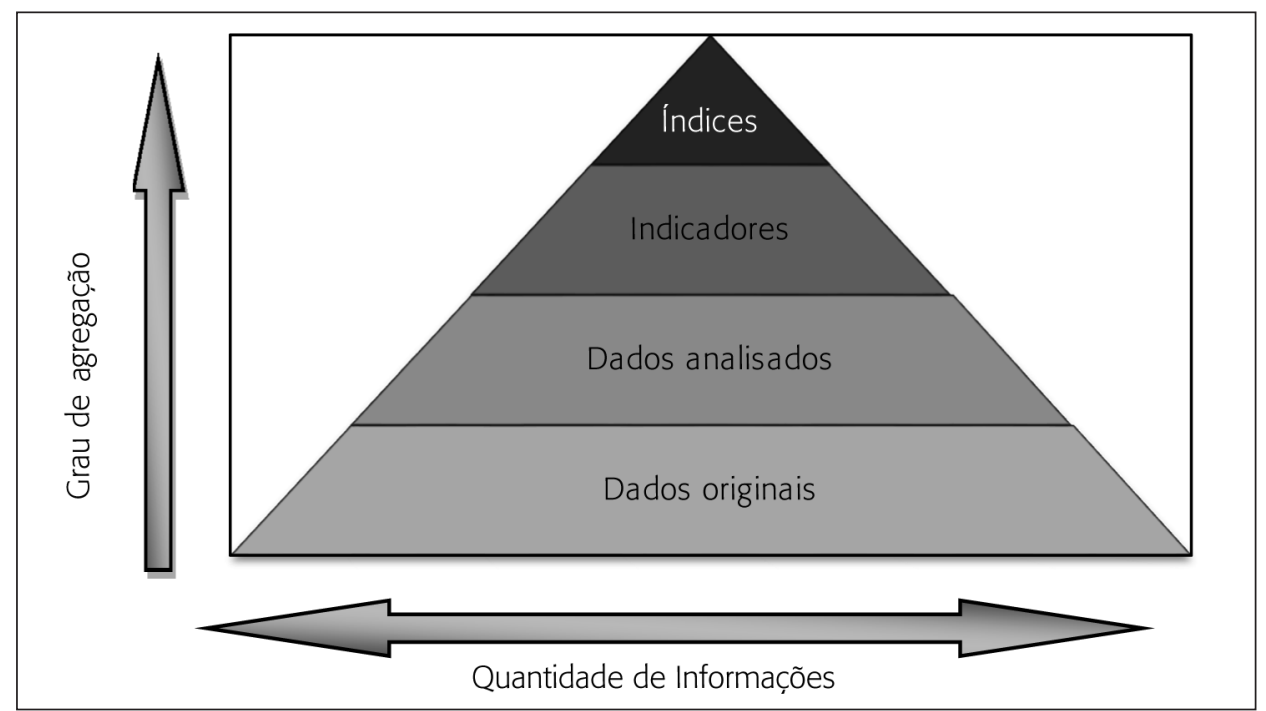

Fonte: Elaboração dos autores a partir de Brasil (2010:29).

Ilustra-se na figura 2 o diagrama da formação do IGovP:

Figura 2

Diagrama da formação do IGovP

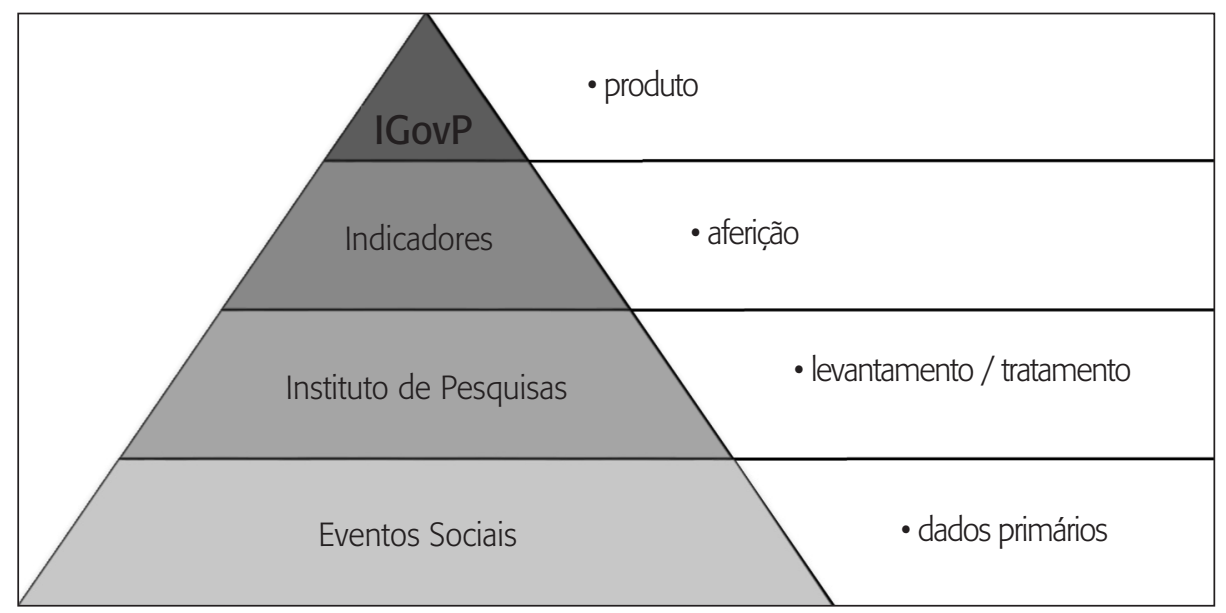

Fonte: Elaboração dos autores.

No quadro 4 são elencados os indicadores (insumos) do IGovP, determinados em função dos princípios de governança pública adotados no referencial teórico, sendo definido o que cabe a cada um deles medir e de que fonte os dados são selecionados. 
Quadro 4

\section{Indicadores propostos para a formação do índice IGovP}

\begin{tabular}{|c|c|c|}
\hline Princípio a ser avaliado & Indicadores propostos para agregação & Fonte de pesquisa dos dados \\
\hline \multirow[t]{2}{*}{ 1. Efetividade } & $\begin{array}{l}\text { 1.1 Renda média domiciliar per capita } \\
\text { percentual }\end{array}$ & $\begin{array}{l}\text { IBGE - Pesquisa Nacional por Amostra de Domicílios } \\
\text { (Pnad). Disponível em: <http://tabnet.datasus.gov.br/ } \\
\text { cgi/tabcgi.exe?ibge/censo/cnv/rendauf.def>. }\end{array}$ \\
\hline & $\begin{array}{l}1.2 \text { Índice de Desenvolvimento Humano } \\
\text { Municipal (IDH-M) }\end{array}$ & $\begin{array}{l}\text { Programa das Nações Unidas para o Desenvolvimento } \\
\text { (Pnud) Brasil. Disponível em: <www.pnud.org.br /atlas/ } \\
\text { ranking/Riiianking-IDHM-UF-2010.aspx>. }\end{array}$ \\
\hline 2. Transparência e & 2.1 Índice de Transparência & Associação Contas Abertas. \\
\hline Accountability & & $\begin{array}{l}\text { Responsabilidade: Comitê de Transparência. Disponível } \\
\text { em: <http://indicedetransparencia.com/edicao-2010/>. }\end{array}$ \\
\hline \multirow[t]{2}{*}{ 3. Participação } & $\begin{array}{l}\text { 3.1 Percentual de Eleitorado Votos } \\
\text { Válidos versus Eleitores Aptos } \\
\text { Percentual } 1 \text { ํTurno }\end{array}$ & $\begin{array}{l}\text { Tribunal Superior Eleitoral. Disponível em: <www.t } \\
\text { se.jus.br/eleicoes/eleicoes-anteriores/eleicoes-2010/ } \\
\text { estatisticas>. }\end{array}$ \\
\hline & $\begin{array}{l}\text { 3.2 Taxa de participação em Conselhos } \\
\text { Nacionais e Estaduais }\end{array}$ & $\begin{array}{l}\text { IBGE. Disponível em: <http://servicodados.ibge.gov. } \\
\text { br/ Download/Download.ashx?u=ftp.ibge.gov.br/Perfil_ } \\
\text { Estados/2012/Base_ESTADIC_2012_xls.zip>. }\end{array}$ \\
\hline \multirow[t]{3}{*}{ 4. Equidade } & $\begin{array}{l}4.1 \text { Índice de Gini da distribuição do } \\
\text { rendimento mensal das pessoas de } 10 \\
\text { anos ou mais de idade, ocupadas na } \\
\text { semana de referência, com rendimento } \\
\text { de trabalho }\end{array}$ & $\begin{array}{l}\text { IBGE. Síntese de Indicadores do Censo Demográfico. } \\
\text { Disponível em: <ftp://ftp.ibge. gov.br/Censos/ } \\
\text { Censo_Demografico_2010/Resultados_do_Universo/ } \\
\text { Resultados_preliminares_sobre_Rendimentos/tabelas_ } \\
\text { pdf/tab1_8_10.pdf>. }\end{array}$ \\
\hline & $\begin{array}{l}\text { 4.2 Taxa de analfabetismo } \\
\text { População de } 15 \text { anos ou mais por } \\
\text { unidade da Federação segundo região }\end{array}$ & $\begin{array}{l}\text { IBGE. Censo Demográfico 2010-Datasus. Disponível } \\
\text { em: <http://tabnet.datasus.gov.br/cgi/tabcgi.exe?ibge/ } \\
\text { censo/cnv/alfuf.def>. }\end{array}$ \\
\hline & $\begin{array}{l}\text { 4.3 Taxa de desemprego: percentual } \\
\text { da população de } 16 \text { anos e mais, } \\
\text { economicamente ativa, desocupada }\end{array}$ & $\begin{array}{l}\text { IBGE. Censo Demográfico 2010-Datasus. Disponível } \\
\text { em: <http://tabnet.datasus.gov.br/cgi/tabcgi.exe?ibge/ } \\
\text { censo/cnv/desempruf.def>. }\end{array}$ \\
\hline \multirow[t]{3}{*}{$\begin{array}{l}\text { 5. Legalidade, Ética, } \\
\text { Integridade }\end{array}$} & $\begin{array}{l}\text { 5.1 Taxa de Aprovação das contas } \\
\text { pelo TCE/TCU, em obediência à Lei de } \\
\text { Responsabilidade Fiscal }\end{array}$ & $\begin{array}{l}\text { Sítios institucionais dos respectivos TCEs e TCU. } \\
\text { Diários Oficiais dos estados. }\end{array}$ \\
\hline & 5.2 Direitos Humanos & IBGE. Censo Demográfico 2010-Datasus. \\
\hline & $\begin{array}{l}\text { Taxa de trabalho infantil segundo região/ } \\
\text { unidade da Federação }\end{array}$ & $\begin{array}{l}\text { Disponível em: <http://tabnet.datasus.gov.br/cgi/tabcgi. } \\
\text { exe?ibge/censo/cnv/trabinfuf.def>. }\end{array}$ \\
\hline
\end{tabular}

Fonte: Elaboração dos autores a partir do referencial citado.

O modelo lógico de desenvolvimento IGovP é descrito no quadro 5, em complemento ao quadro 4, relacionando as variáveis e os indicadores a serem ponderados, confirmando que, não obstante seu ineditismo, é possível a criação de um índice para mensurar o grau de governança dos entes federativos, e fazer isso de forma simples, consistente e confiável. 
Quadro 5

\section{Composição do IGovP e seus critérios de ponderação - ano 2010}

\begin{tabular}{|c|c|c|c|c|c|}
\hline $\begin{array}{l}\text { Princípios da } \\
\text { Governança Pública }\end{array}$ & Peso & Agregação das Variáveis & Peso & Composição das Variáveis (\%) & Peso \\
\hline \multirow[t]{2}{*}{ 1. Efetividade } & \multirow[t]{2}{*}{0,20} & $\begin{array}{l}\text { 1.1 Acesso à Renda } \\
\text { Lógica: quanto maior, melhor }\end{array}$ & 0,50 & 1.1.2 Renda média domiciliar per capita & 1,00 \\
\hline & & $\begin{array}{l}\text { 1.2 Desenvolvimento Humano } \\
\text { Lógica: quanto mais próximo de } 1, \\
\text { maior o desenvolvimento }\end{array}$ & 0,50 & $\begin{array}{l}\text { 1.2.1 Desenvolvimento Humano } \\
\text { Municipal (IDH-M) }\end{array}$ & 1,00 \\
\hline $\begin{array}{l}\text { 2. Transparência e } \\
\text { Accountability }\end{array}$ & 0,20 & $\begin{array}{l}2.1 \text { Acesso à informação e prestação } \\
\text { de contas } \\
\text { Lógica: quanto maior, melhor }\end{array}$ & 1,00 & $\begin{array}{l}\text { 2.1.1 Índice de Transparência } \\
\text { Contas Abertas }\end{array}$ & 1,00 \\
\hline \multirow[t]{2}{*}{ 3. Participação } & \multirow[t]{2}{*}{0,20} & $\begin{array}{l}\text { 3.1 Eleitorado Votos Efetivos Válidos } \\
\text { versus Eleitores Aptos 1o Turno } \\
\text { Lógica: quanto maior, melhor }\end{array}$ & 0,80 & $\begin{array}{l}\text { 3.1.1 Votos Efetivos Válidos sobre total } \\
\text { do eleitorado } \\
\text { 1ํ Turno das Eleições }\end{array}$ & 1,00 \\
\hline & & $\begin{array}{l}\text { 3.2 Participação Social em Conselhos } \\
\text { Lógica: quanto mais instrumentos, } \\
\text { melhor }\end{array}$ & 0,20 & $\begin{array}{l}\text { 3.2.1 Número de instrumentos relativos } \\
\text { aos conselhos Nacionais e Estaduais } \\
\text { Quantidade de Instrumentos: } \\
\text { de } 55 \text { a } 59 \text { - nota } 0,15 \\
\text { de } 61 \text { a } 69 \text { - nota } 0,30 \\
\text { de } 70 \text { a } 73 \text { - nota } 0,50 \\
\text { de } 74 \text { a } 82 \text { - nota } 0,65 \\
\text { de } 83 \text { a } 90 \text { - nota } 0,85 \\
\text { maior ou igual a } 91 \text { - nota } 1,00\end{array}$ & 1,00 \\
\hline \multirow[t]{4}{*}{ 4. Equidade } & \multirow[t]{4}{*}{0,20} & $\begin{array}{l}\text { 4.1 Desigualdade de Renda por } \\
\text { Unidade da Federação } \\
\text { Índice de Gini } \\
\text { Lógica: quanto mais próximo do } \\
\text { zero, melhor a distribuição de renda } \\
\text { no país }\end{array}$ & 0,40 & $\begin{array}{l}\text { 4.1.1 Índice de Gini da distribuição } \\
\text { do rendimento nominal mensal de } \\
\text { todos os trabalhos das pessoas de } \\
10 \text { anos ou mais de idade, ocupadas } \\
\text { na semana de referência, com } \\
\text { rendimento de trabalho }\end{array}$ & 1,00 \\
\hline & & $\begin{array}{l}4.2 \text { População sem acesso às } \\
\text { condições de vida digna } \\
\text { Lógica: quanto menor, melhor }\end{array}$ & 0,60 & $\begin{array}{l}\text { 4.2.1 População de } 16 \text { anos e mais, } \\
\text { economicamente ativa, desocupada }\end{array}$ & 0,25 \\
\hline & & & & 4.2.2 Taxa de analfabetismo & 0,25 \\
\hline & & & & $\begin{array}{l}\text { 4.2.3 Taxa da população vivendo com } \\
\text { renda inferior a } 1 / 4 \text { do salário mínimo } \\
\text { (pobreza extrema) }\end{array}$ & 0,50 \\
\hline \multirow[t]{2}{*}{$\begin{array}{l}\text { 5. Legalidade, Ética e } \\
\text { Integridade }\end{array}$} & \multirow[t]{2}{*}{0,20} & $\begin{array}{l}\text { 5.1 Cumprimento da LRF Aprovação } \\
\text { das contas anuais pelos TCEs/TCU } \\
\text { Lógica: quanto maior, melhor }\end{array}$ & 0,50 & $\begin{array}{l}\text { 5.1.1 Aprovação das contas pelos } \\
\text { TCEs/TCU } \\
\text { Se regulares - nota 1,00 } \\
\text { Se regulares com ressalvas, } \\
\text { recomendações ou determinações - } \\
\text { nota 0,50 } \\
\text { Se irregulares - nota } 0\end{array}$ & 1,0 \\
\hline & & $\begin{array}{l}5.2 \text { Direitos Humanos } \\
\text { Lógica: Quanto menor, melhor }\end{array}$ & 0,50 & 5.2.1 Taxa de trabalho Infantil & 1,0 \\
\hline
\end{tabular}

Fonte: Elaboração dos autores. 
Como comentado, o IGovP resulta da somatória da pontuação de cinco indicadores, a saber: (1) Efetividade; (2) Transparência e Accountability; (3) Participação; (4) Equidade; e (5) Legalidade/Ética/Integridade.

Esses cinco indicadores formam os pilares basilares da avaliação, fundamentados nos princípios da governança pública selecionados neste estudo. O peso atribuído a cada indicador é de $20 \%$, por se entender que todos são igualmente importantes para alcançar a efetividade das políticas públicas. Ao se privilegiar essa efetividade, entende-se que a avaliação recairá muito mais sobre as mudanças decorrentes das políticas públicas, observadas empiricamente na sociedade, do que na mera aferição de sua execução.

Cada pilar (princípio) compõe um indicador do IGovP, e cada um desses indicadores é formado a partir da agregação de variáveis que, por sua vez, possuem seus próprios indicadores, cujos valores são obtidos junto aos institutos de pesquisa e organizações referenciadas.

A fórmula para o cálculo do IGovP, conforme a equação 1, consiste na somatória dos escores de cada indicador de tal forma que, levando-se em consideração a pontuação máxima (20\% com que cada indicador contribui para o cálculo do índice final), corresponde a 100\% da nota ou, considerando-se os valores absolutos, à unidade.

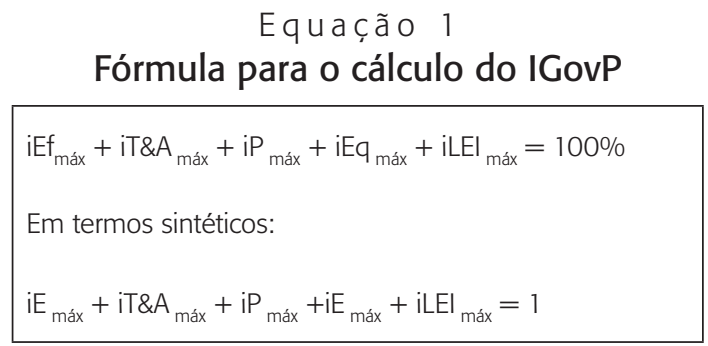

Fonte: Elaboração dos autores.

Onde:

$\mathrm{iEf}_{\mathrm{m}} \quad=$ valor máximo do Indicador Efetividade $\quad 20 \%$ do IGovP

iT\&A $_{\text {máx }}=$ valor máximo do Indicador Transparência e Accountability $\quad 20 \%$ do IGovP

$\mathrm{iP}_{\text {máx }}=$ valor máximo do Indicador Participação $20 \%$ do IGovP

$\mathrm{iEq}_{\text {máx }} \quad=$ valor máximo do Indicador Equidade $20 \%$ do IGovP

iLEI $_{\text {máx }}=$ valor máximo do Indicador Legalidade/Ética/Integridade $\quad 20 \%$ do IGovP

Em termos matemáticos, a equação 2 apresenta a ponderação entre as notas e os respectivos pesos atribuídos, sendo a fórmula do IGovP a seguinte:

Equação 2

Fórmula da nota final do índice IGovP 2010

$$
\text { IGovP }=\sum_{i=1}^{5}\left(N_{i}\right) \times\left(p_{i}\right)
$$

Fonte: Elaboração dos autores. 
Onde:

IGovP = Índice de Governança Pública

$\mathrm{Ni} \quad=$ Nota obtida no pilar i

pi $\quad=$ Peso atribuído ao pilar i

O cálculo dos resultados de cada pilar/indicador é ponderado a partir das variáveis agregadas e dos indicadores constantes do quadro 5. A mensuração de cada pilar que compõe o IGovP é detalhada na equação 3 a seguir:

1) A nota do Pilar Efetividade resulta da média ponderada das variáveis agregadas que o compõem, no caso: (i) acesso à renda (com peso 0,50); e (ii) desenvolvimento humano (com peso 0,50 ), de tal forma que:

Equação 3

Ponderação da nota percentual do pilar efetividade

$\left.\begin{array}{l}\text { Nota (\%) Pilar Efetividade }=\left[\frac{(\%) \text { Acesso à Renda * } \mathrm{P} 1+(\%) \text { Desenv Humano } * \text { P2 }}{\sum \text { pesos }}\right] \\ P 1=P 2=0,50\end{array}\right]$

Fonte: Elaboração dos autores.

1.1) A nota de cada uma das variáveis agregadas que compõem o pilar Efetividade também resulta da média ponderada das notas de seus indicadores, conforme a equação 4:

Equação 4

Composição da nota da variável acesso à renda

Nota $(\%)$ Acesso à Renda $=\frac{(\% \text { Renda média domiciliar per capita } * \text { P.1.1) }}{\sum \text { Pn }}$
$P .1 .1=1$

Fonte: Elaboração dos autores.

2) A nota do pilar Transparência e Accountability (Transp \& Account) resulta da média ponderada da variável agregada que o compõe, no caso: acesso à informação e prestação de contas (com peso 1), de tal forma que:

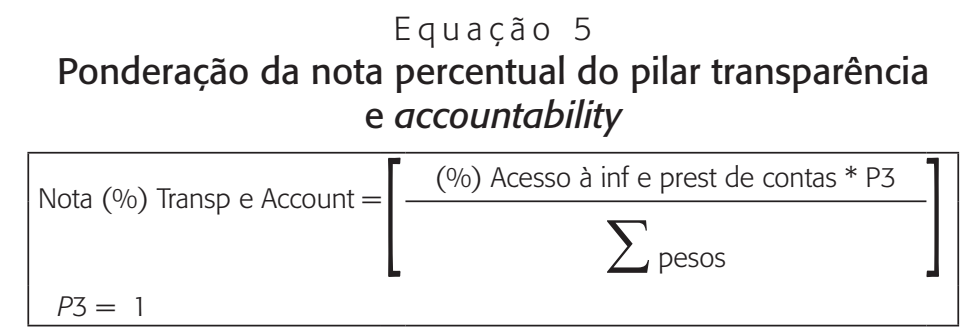

Fonte: Elaboração dos autores. 
3) A nota do pilar Participação resulta da média ponderada das variáveis agregadas que o compõem, no caso: (i) eleitorado votos válidos efetivos versus eleitores aptos no 1ํo turno da eleição (Votos Efetivos $1^{\circ}$ turno), com peso 0,80, e (ii) participações em conselhos e comissões (Part Conselhos), com peso 0,20, de tal forma que:

\section{Equação 6}

Ponderação da nota percentual do pilar participação

Nota (\%) Participação $=\left[\frac{(\%) \text { Votos Efetivos } 1^{\circ} \text { turno * P4 + (\%) Part Conselhos * P5 }}{\sum_{\text {pesos }}}\right]$
$P 4=0,80$
$P 5=0,20$

Fonte: Elaboração dos autores.

4) A nota pilar Equidade resulta da média ponderada das variáveis agregadas que a compõem, no caso: (i) desigualdade de renda (Gini), com peso 0,40, e (ii) população sem acesso às condições de vida digna, com peso 0,60 , de tal forma que:

\section{Equação 7}

Ponderação da nota percentual do pilar equidade

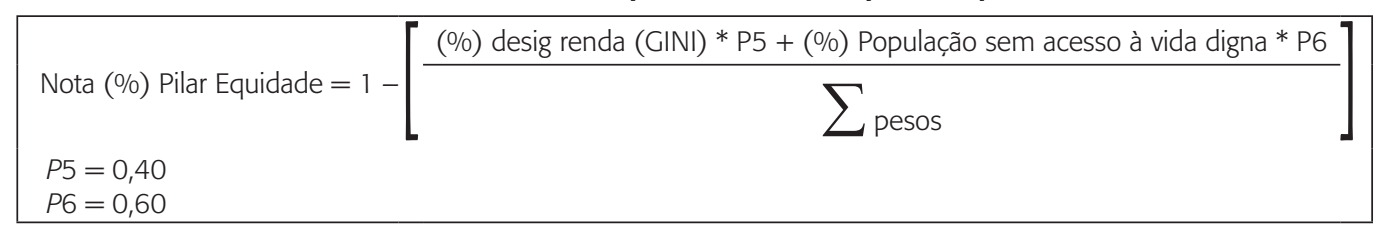

Fonte: Elaboração dos autores.

Observe-se em registro que, na fórmula de cálculo do indicador equidade, a lógica é inversa, ou seja, quanto menor, melhor, por isso o resultado deve ser subtraído da unidade.

5) A nota do último pilar: Legalidade/Ética/Integridade (L.E.I), resulta da média ponderada das variáveis agregadas que o compõem, no caso: (i) cumprimento da Lei de Responsabilidade Fiscal (LRF), com peso 0,50; e (ii) Direitos Humanos, com peso 0,50, de tal forma que:

\section{Equação 8}

\section{Ponderação da nota percentual do pilar legalidade/ética/integridade}

Nota (\%) Pilar L.E.I. $=\left[\frac{(\%) \text { Cumprimento da LRF * P7 + [1- ((\%) Direitos Humanos * P8) }]}{\sum \text { pesos }}\right]$
$\begin{aligned} & P 7=0,50 \\ & P 8=0,50\end{aligned}$

Fonte: Elaboração dos autores. 
No cálculo da variável direitos humanos, a lógica é também inversa, pois, em se tratando de trabalho infantil, quanto menor, melhor, por isso o resultado foi subtraído da unidade.

O IGovP é um índice sintético e, portanto, tem variação de 0 até 1 , sendo que, quanto mais próximo de 1 for a nota alcançada pelo ente federativo, maior o grau de governança pública e, em contrapartida, quanto mais perto de zero, menor esse grau.

Para enquadramento das faixas de aferição, adota-se o mesmo escalonamento do IDHM e justifica-se essa adoção, por se tratar de uma ferramenta consagrada, reconhecida, já testada e utilizada mundialmente.

Outra vantagem da adoção da escala do IDHM é sua contemporaneidade, uma vez que em 2013 o Pnud Brasil, o Ipea e a Fundação João Pinheiro assumiram o desafio de adaptar a metodologia do IDH global para calcular o IDH Municipal (IDHM) dos 5.565 municípios brasileiros a partir de dados do Censo Demográfico de 2010 (Pnud, 2013:27).

A figura 3 apresenta as escalas e faixas de aferição para os resultados do IGovP:

Figura 3

Escala das faixas de resultado do IGovP

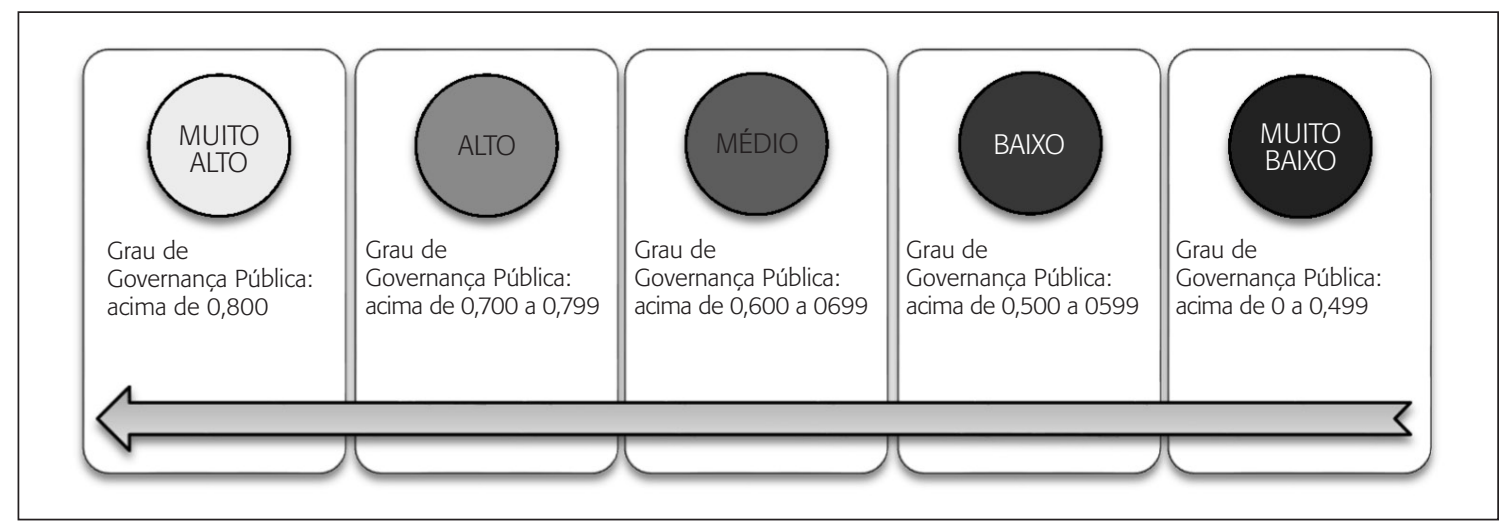

Fonte: Elaboração dos autores.

Convém salientar que a adoção de indicadores não é livre de críticas, haja vista suas limitações naturais. Observe-se o que adverte Jannuzzi (2002) quanto à sua utilização tanto na pesquisa acadêmica como na formulação e avaliação de políticas públicas:

(...) o indicador social deve gozar de uma série de propriedades. Além da sua relevância para discussão da agenda da política social, de sua validade em representar o conceito indicado e da confiabilidade dos dados usados na sua construção, um indicador social deve:

1. ter um grau de cobertura populacional adequado aos propósitos a que se presta; 
2. ser sensível a políticas públicas implementadas;

3. ser específico a efeitos de programas setoriais;

4. ser inteligível para os agentes e públicos-alvo das políticas;

5. ser atualizável periodicamente, a custos razoáveis;

6. ser amplamente desagregável em termos geográficos, sociodemográficos e socioeconômicos;

7. gozar de certa historicidade para possibilitar comparações no tempo (Jannuzzi, 2002:56).

Ademais, conforme argumenta Telles (2003:4), "indicadores não medem a realidade, mas participam da construção social da realidade". Essa construção não pode relacionar-se simplesmente ao que a autora denomina de o "mundo das representações", mas sim com as práticas e disputas, mediações e conexões, articulações e toda uma rede social (ao mesmo tempo técnica, científica, política, institucional).

No entanto, apesar das limitações e críticas, não se pode deixar de apresentar essa iniciativa no sentido de aferição do grau de governança pública - não apenas com intuito de obter-se uma medição, mas para servir como ferramenta de monitoramento da evolução da efetividade das políticas públicas e da capacidade dos governos em implementá-las.

Concordando sobre todos os cuidados que se deve ter ao tomar decisões fundamentadas em indicadores, fica, no entanto, a questão: como controlar/melhorar sem medir?

O erro, se ocorrer, por certo será menos maléfico à sociedade do que não se terem parâmetros, pois sem os indicadores não existe possibilidade, ainda que "eventualmente limitada", de avaliação e comparação e, por conseguinte, também não se estimulará a concorrência saudável estabelecida a partir dos processos avaliativos.

Na parte 5 deste estudo são expostos os resultados auferidos a partir do desenvolvimento do Índice de Avaliação da Governança Pública (IGovP).

\section{Resultados e conclusões}

Aplicando-se a metodologia desenvolvida, o IGovP foi calculado de acordo com os parâmetros e procedimentos previstos e seus resultados trazem à realidade uma medição inédita que expõe um dos possíveis retratos do Brasil.

Na tabela 1 demonstram-se os resultados do IGovP, de acordo com os escores auferidos pelos diferentes entes federativos.

Consta no apêndice tabela com a aplicação de toda a metodologia de cálculos e os escores das variáveis agregadas, pesos e ponderação dos indicadores que resultaram na composição do IGovP de cada ente federativo. 
Tabela 1

Notas obtidas do IgovP por ente federativo e regiões geográficas

\begin{tabular}{|c|c|c|c|c|c|c|}
\hline \multirow[b]{3}{*}{ FORMAÇÃO DO IGovP } & \multirow{3}{*}{$\begin{array}{l}\text { VALOR DO } \\
\text { ÍNDICE IGovP } \\
2010\end{array}$} & \multicolumn{5}{|c|}{ PRINCÍPIOS DA GOVERNANÇA PÚBLICA } \\
\hline & & \multicolumn{5}{|c|}{ Valor dos Indicadores } \\
\hline & & Efetividade & $\begin{array}{l}\text { Transparência } \\
\text { e Accoutability }\end{array}$ & Participação & Equidade & $\begin{array}{l}\text { Legalidade Ética } \\
\text { Integridade }\end{array}$ \\
\hline Pesos dos Indicadores & $100 \%$ & $20 \%$ & $20 \%$ & $20 \%$ & $20 \%$ & $20 \%$ \\
\hline BRASIL - União & 0,6986 & 0,5938 & 0,7560 & 0,7288 & 0,7117 & 0,7029 \\
\hline Norte & 0,5979 & 0,4903 & 0,4410 & 0,7011 & 0,6665 & 0,6907 \\
\hline Rondônia & 0,6250 & 0,5392 & 0,5380 & 0,6458 & 0,7233 & 0,6786 \\
\hline Acre & 0,5808 & 0,4808 & 0,3820 & 0,6879 & 0,6597 & 0,6937 \\
\hline Amazonas & 0,6184 & 0,4896 & 0,5240 & 0,7316 & 0,6565 & 0,6902 \\
\hline Roraima & 0,5318 & 0,5271 & 0,3310 & 0,6857 & 0,6735 & 0,4416 \\
\hline Pará & 0,6119 & 0,4520 & 0,4650 & 0,7956 & 0,6568 & 0,6902 \\
\hline Amapá & 0,5514 & 0,5268 & 0,3850 & 0,7085 & 0,6814 & 0,4553 \\
\hline Tocantins & 0,5697 & 0,5211 & 0,4620 & 0,7299 & 0,6873 & 0,4485 \\
\hline Nordeste & 0,5859 & 0,4676 & 0,4623 & 0,6553 & 0,6457 & 0,6985 \\
\hline Maranhão & 0,5817 & 0,4242 & 0,5240 & 0,6450 & 0,6191 & 0,6961 \\
\hline Piauí & 0,5421 & 0,4456 & 0,3040 & 0,6337 & 0,6296 & 0,6975 \\
\hline Ceará & 0,5975 & 0,4749 & 0,4180 & 0,7414 & 0,6501 & 0,7031 \\
\hline Rio Grande do Norte & 0,5905 & 0,5016 & 0,3820 & 0,6827 & 0,6721 & 0,7141 \\
\hline Paraíba & 0,6033 & 0,4678 & 0,5070 & 0,6962 & 0,6465 & 0,6990 \\
\hline Pernambuco & 0,6274 & 0,4893 & 0,6910 & 0,5993 & 0,6549 & 0,7024 \\
\hline Alagoas & 0,6437 & 0,4420 & 0,5200 & 0,6784 & 0,6302 & 0,9478 \\
\hline Sergipe & 0,6298 & 0,4851 & 0,4330 & 0,6268 & 0,6499 & 0,9545 \\
\hline Bahia & 0,5636 & 0,4745 & 0,3820 & 0,6206 & 0,6503 & 0,6905 \\
\hline Sudeste & 0,6796 & 0,6601 & 0,5753 & 0,7043 & 0,7453 & 0,7133 \\
\hline Minas Gerais & 0,6629 & 0,5856 & 0,5600 & 0,7245 & 0,7409 & 0,7036 \\
\hline Espírito Santo & 0,6582 & 0,6088 & 0,5360 & 0,7109 & 0,7366 & 0,6986 \\
\hline Rio de Janeiro & 0,6598 & 0,6787 & 0,5090 & 0,6501 & 0,7369 & 0,7245 \\
\hline São Paulo & 0,7174 & 0,7027 & 0,6960 & 0,7187 & 0,7545 & 0,7152 \\
\hline Sul & 0,6976 & 0,6543 & 0,5973 & 0,7742 & 0,7673 & 0,6950 \\
\hline
\end{tabular}




\begin{tabular}{|c|c|c|c|c|c|c|}
\hline \multirow[b]{3}{*}{ FORMAÇÃO DO IGovP } & \multirow{3}{*}{$\begin{array}{l}\text { VALOR DO } \\
\text { ÍNDICE IGovP } \\
2010\end{array}$} & \multicolumn{5}{|c|}{ PRINCÍPIOS DA GOVERNANÇA PÚBLICA } \\
\hline & & \multicolumn{5}{|c|}{ Valor dos Indicadores } \\
\hline & & Efetividade & $\begin{array}{l}\text { Transparência } \\
\text { e Accoutability }\end{array}$ & Participação & Equidade & $\begin{array}{l}\text { Legalidade Ética } \\
\text { Integridade }\end{array}$ \\
\hline Pesos dos Indicadores & $100 \%$ & $20 \%$ & $20 \%$ & $20 \%$ & $20 \%$ & $20 \%$ \\
\hline Paraná & 0,6982 & 0,6359 & 0,6070 & 0,7949 & 0,7595 & 0,6938 \\
\hline Santa Catarina & 0,6963 & 0,6775 & 0,5560 & 0,7689 & 0,7889 & 0,6904 \\
\hline Rio Grande do Sul & 0,7017 & 0,6553 & 0,6290 & 0,7621 & 0,7629 & 0,6991 \\
\hline Centro-Oeste & 0,6642 & 0,6574 & 0,4583 & 0,7768 & 0,7309 & 0,6979 \\
\hline Mato Grosso do Sul & 0,6396 & 0,6002 & 0,4440 & 0,7123 & 0,7392 & 0,7021 \\
\hline Mato Grosso & 0,6391 & 0,5833 & 0,3930 & 0,7870 & 0,7400 & 0,6925 \\
\hline Goiás & 0,6171 & 0,6032 & 0,5160 & 0,7776 & 0,7475 & 0,4411 \\
\hline Distrito Federal & 0,7339 & 0,9120 & 0,4800 & 0,8356 & 0,7249 & 0,7171 \\
\hline
\end{tabular}

Fonte: Elaboração dos autores.

A figura 4 ilustra a distribuição geográfica dos resultados do IGovP:

Figura 4

\section{Mapeamento do IGovP no Brasil}

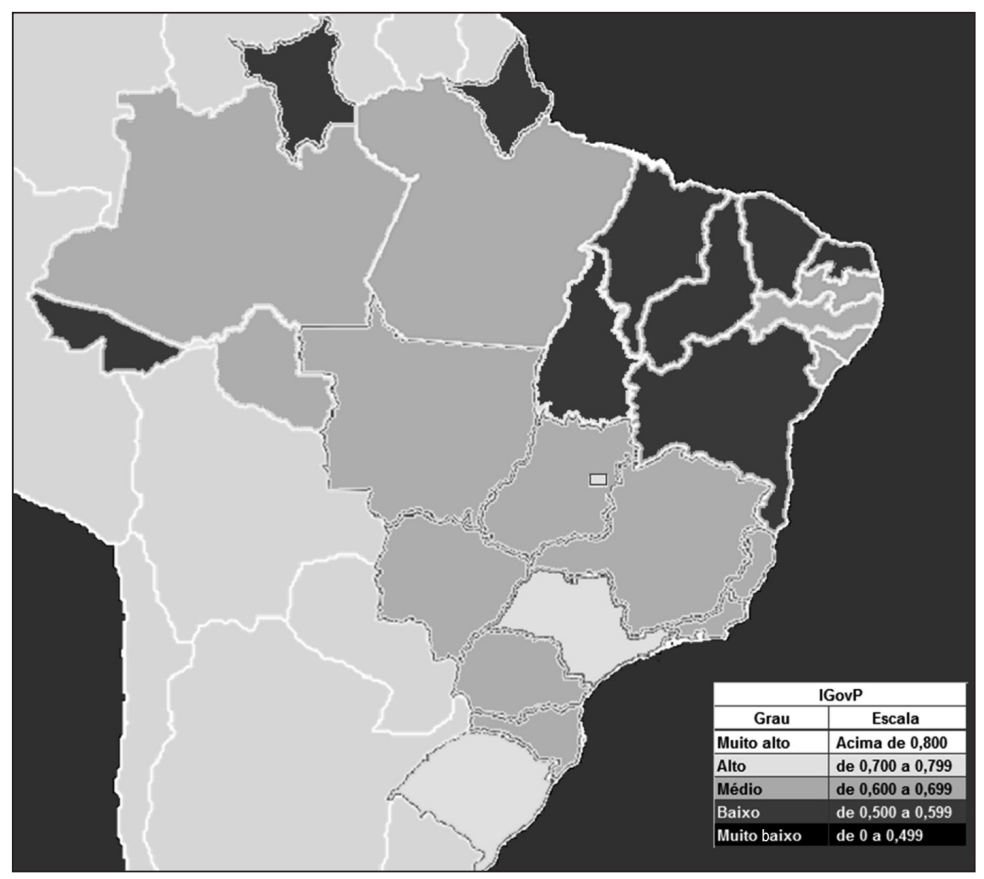

Fonte: Elaboração dos autores. 
A partir dos resultados obtidos, e a título de ilustração, apresenta-se um ranking dos entes federativos e as frequências de enquadramento em função do escalonamento previsto, conforme constam na tabela 2 e no gráfico 1 :

Tabela 2

Ranking IGovP - por DF e estados da Federação

\begin{tabular}{|c|c|c|c|}
\hline Ordem & Estado & IGovP & Escala \\
\hline $1 \stackrel{\circ}{1}$ & Distrito Federal & 0,7339 & alto \\
\hline $2^{\circ}$ & São Paulo & 0,7174 & alto \\
\hline 3 웅 & Rio Grande do Sul & 0,7017 & alto \\
\hline $4^{\circ}$ & Paraná & 0,6982 & médio \\
\hline 50 & Santa Catarina & 0,6963 & médio \\
\hline 60 & Minas Gerais & 0,6629 & médio \\
\hline $7 ㅇ$ & Rio de Janeiro & 0,6598 & médio \\
\hline $8 \circ$ & Espírito Santo & 0,6582 & médio \\
\hline 9음 & Alagoas & 0,6437 & médio \\
\hline 10 & Mato Grosso do Sul & 0,6396 & médio \\
\hline 110 & Mato Grosso & 0,6391 & médio \\
\hline $12^{\circ}$ & Sergipe & 0,6298 & médio \\
\hline 130 & Pernambuco & 0,6274 & médio \\
\hline $14^{\circ}$ & Rondônia & 0,6250 & médio \\
\hline $15^{\circ}$ & Amazonas & 0,6184 & médio \\
\hline 160 & Goiás & 0,6171 & médio \\
\hline $17^{\circ}$ & Pará & 0,6119 & médio \\
\hline $18^{\circ}$ & Paraíba & 0,6033 & médio \\
\hline 19음 & Ceará & 0,5975 & baixo \\
\hline $20^{\circ}$ & Rio Grande do Norte & 0,5905 & baixo \\
\hline 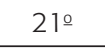 & Maranhão & 0,5817 & baixo \\
\hline $22^{\circ}$ & Acre & 0,5808 & baixo \\
\hline $23 ㅇ$ & Tocantins & 0,5697 & baixo \\
\hline $24^{\circ}$ & Bahia & 0,5636 & baixo \\
\hline $25^{\circ}$ & Amapá & 0,5514 & baixo \\
\hline $26^{\circ}$ & Piauí & 0,5421 & baixo \\
\hline $27^{\circ}$ & Roraima & 0,5318 & baixo \\
\hline
\end{tabular}

Fonte: Elaboração dos autores.

Os resultados demonstram que nenhum ente federativo se enquadrou no grau de governança muito baixo, com escores inferiores a 0,5000 . Também nenhum deles atingiu grau muito alto, com nota superior a 0,8000 .

\section{Gráfico 1}

IGovP - escalas e frequências nos estados

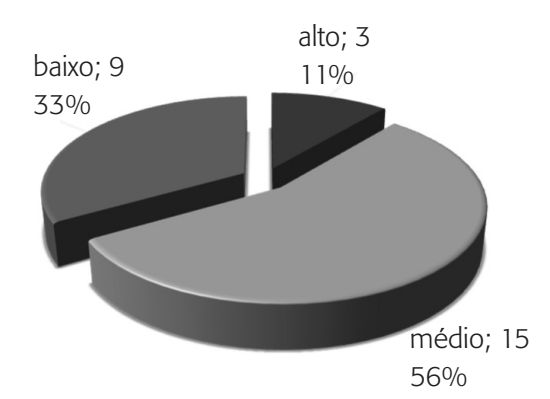


Isso se justifica pela própria lógica do IGovP, que pondera na razão de $20 \%$, cinco indicadores resultantes da agregação de variáveis distintas e um desempenho baixo em alguns dos indicadores influencia no resultado final do índice.

Observa-se na tabela 1 que, em certas ocasiões, entes federativos obtiveram, em algum indicador em particular, escores nas escalas de grau muito alto ou grau muito baixo, mas que na ponderação geral enquadrou-se em outro resultado.

Explicando melhor, tem-se como exemplo a análise do resultado do IGovP do Distrito Federal (tabela 1), que alcançou escores de dois indicadores (efetividade, com 0,9120, e participação, com 0,8356 ) na faixa do grau muito alto de governança pública; dois indicadores (equidade, com 0,7249, e legalidade, ética e integridade, com 0,7171) na faixa do alto grau; porém o escore do indicador transparência/accountability situado na escala do grau muito baixo, com 0,4800. No entanto, em razão da ponderação (20\%) de participação de cada indicador, resultou no grau de IGovP de 0,7339, na faixa do "alto grau" de governança pública.

O Distrito Federal obteve o melhor resultado entre todos os entes federativos, e, entre os estados, São Paulo e Rio Grande do Sul ficaram com o IGovP acima de 0,700, encerrando o grupo dos estados com resultado de "alto grau" de governança.

São Paulo, por sua vez, alcançou graus acima de 0,7000 em todos os pilares, exceto para o indicador transparência e accountability (0,6960). O estado do Rio Grande do Sul, apesar de não alcançar a maior nota em nenhum dos indicadores do IGovP, sustentou uma regularidade entre os melhores escores.

Mesmo que as regiões geográficas não sejam consideradas entes federativos, optou-se, a título de ilustração, por apresentar o ranking da União e grandes regiões, conforme o gráfico 2:

Gráfico 2

IGovP - Ranking Brasil e regiões geográficas

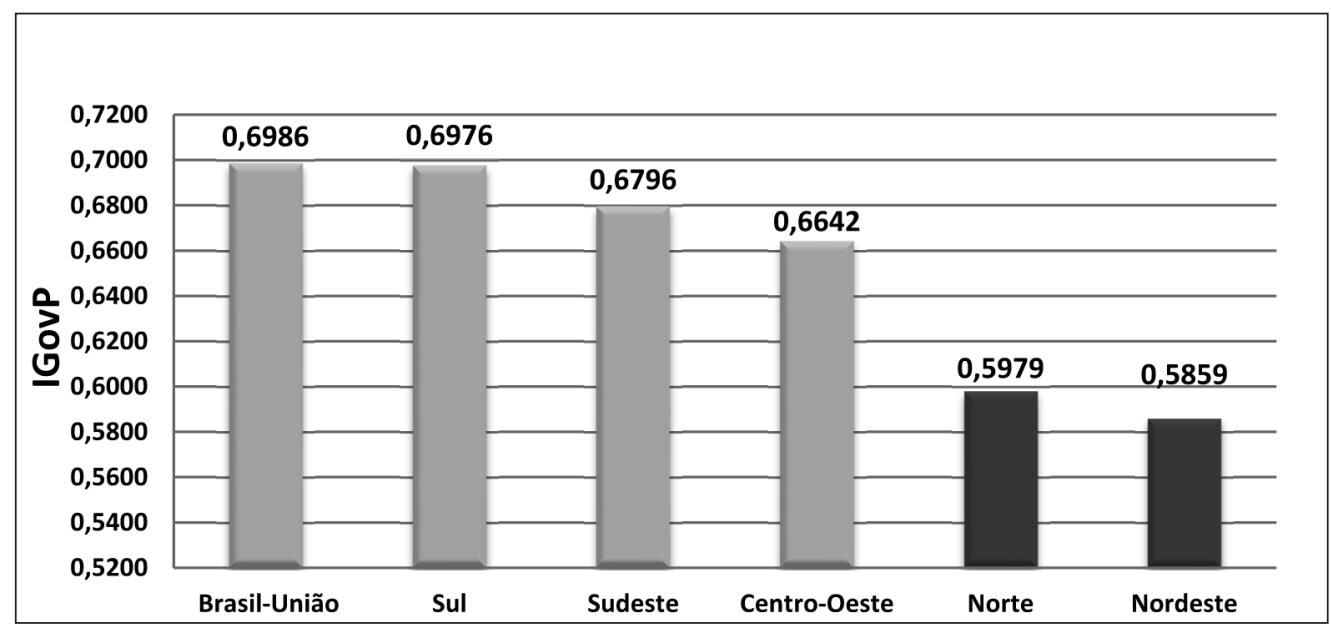

Fonte: Elaboração dos autores. 
O gráfico 2 evidencia que a União alcançou o melhor escore, postando-se na faixa do nível médio do IGovP, seguida de perto pela Região Sul.

Com relação ao ranking das regiões geográficas, a diferença entre a nota alcançada pela Região Sul $(0,6976)$ e pela Região Nordeste $(0,5859)$ foi de 0,1118 ponto ou $16,02 \%$.

Diferenças essas que apontam para desigualdades já amplamente conhecidas na história brasileira, para as quais a solução, na visão de Spink (2012:363), perpassa pela construção de nova relação, "especialmente uma que assume a responsabilidade de agir em relação às desigualdades duráveis, o que certamente não é uma tarefa fácil".

A visão do grau de governança alcançado possibilita aos gestores públicos avaliar a efetividade das ações realizadas e refletir sobre os bons e maus desempenhos. Além disso, representa uma ferramenta de comparação com o desempenho de outros entes, o que permitirá inclusive um intercâmbio de boas práticas.

Quanto ao controle social, o objetivo também foi atingido, visto que as informações disponibilizadas pelo cálculo do IGovP possibilitam uma visão do desempenho de cada ente, o que resulta na possibilidade de controle, comparação e questionamentos.

Um dos pontos fortes do IGovP é seu potencial de informação, uma vez que os indicadores permitem o entendimento imediato devido à sua vocação comparativa. Nesse sentido, julga-se que a metodologia do IGovP é pertinente, que a ferramenta é simples e que os resultados são confiáveis e aderentes à realidade observada.

Isso não quer dizer que o assunto se esgota aqui, ao contrário, ele apenas se inicia e está longe de ser encerrado. Certamente, inúmeras sugestões de melhorias podem e devem ser apresentadas para o cálculo do IGovP, que não pretende ser uma proposta estanque, finita e acabada, e sim aberta ao debate da comunidade acadêmica e da sociedade, na expectativa de receber sugestões que lhe permitam cumprir seu papel avaliativo.

Um índice deve obedecer aos critérios do que se pretende medir, e isto muda sempre que se alteram os direcionamentos políticos, o que significa que, dependendo dos resultados esperados para determinado programa, o índice pode sofrer alterações na definição das variáveis agregadas de seus indicadores.

O fato de se ter selecionado a variável renda média domiciliar per capita para calcular um dos indicadores do pilar Efetividade — o de acesso à renda, e não o PIB per capita — resulta de um direcionamento mais focado nas políticas sociais de melhoria na distribuição de renda e menos centradas nos aspectos econômicos.

Assim, são plenamente aceitáveis alterações nos componentes dessas variáveis em função de novas definições de políticas públicas e das metas governamentais. No momento as políticas públicas sociais direcionam-se à erradicação da pobreza, o que se faz, por exemplo, por meio de uma melhor distribuição de renda. Então, a variável renda foi privilegiada no cálculo do IGovP.

O que não se pode é deixar de medir, de divulgar e de estimular a participação social, devendo-se, sim, apresentar mecanismos apropriados para sua análise e intervenção. O IGovP 
expõe as disparidades entre os entes federativos e os relaciona com os velhos problemas da má distribuição de renda, da falta de acesso à educação, à saúde, ao trabalho, que resultam em menor desenvolvimento para o país.

A título de recomendação para novos estudos, uma pesquisa que contemplasse a formação de um índice de governança pública no âmbito municipal seria muito proveitosa.

Seria igualmente importante desenvolver indicadores para avaliar o grau de governança de órgãos e empresas públicas, de forma semelhante ao que se observa nas empresas privadas com a governança corporativa.

Finalmente, espera-se que os resultados do estudo possam servir de estímulo ao controle social, à maior participação e à conscientização de que os frutos da efetividade das ações governamentais somente serão colhidos quando a sociedade puder assumir plenamente sua cidadania.

\section{Referências}

ANDRADE, Adriana; ROSSETTI, José P. Governança corporativa. São Paulo: Atlas, 2004.

ANDRADE, Adriana; ROSSETTI, José P. Governança corporativa: fundamentos, desenvolvimento e tendências. 2. ed. São Paulo: Atlas, 2009.

ASSOCIAÇÃO CONTAS ABERTAS. Índice de transparência 2010. Avaliação dos portais de transparência dos estados brasileiros e do Distrito Federal. Brasília, 2010.

BANCO MUNDIAL. Relatório sobre o desenvolvimento mundial 2006. Disponível em: < http://siteresources.worldbank.org/INTWDR2006/Resources/477383-1127230817535/0821364154.pdf>. Acesso em: 11 mar. 2014.

BORGES, Luiz F. X.; SERRÃO, Carlos F. de B. Aspectos de governança corporativa moderna no Brasil. Revista do BNDES, Rio de Janeiro, v. 12, n. 24, p. 111-148, dez. 2005.

BRASIL. Constituição (1988). Constituição da República Federativa do Brasil: promulgada em 5 de outubro de 1988, com as alterações adotadas pelas Emendas Constitucionais de n. 1, de 1992, a 38, de 2002, e pelas Emendas Constitucionais de Revisão de n. 1 a 6, de 1994. 19. ed. Brasília: Câmara dos Deputados, Coordenação de Publicações, 2002.

BRASIL. Secretaria de Planejamento e Investimentos Estratégicos. Indicadores de programas: guia metodológico. Brasília: Ministério do Planejamento, Orçamento e Gestão (MPOG), 2010.

BRESSER-PEREIRA, Luiz C. Reforma do Estado para a cidadania: a reforma gerencial brasileira na perspectiva internacional. 34. ed. São Paulo; Brasília: Enap, 1998.

CADBURY COMMITTEE. Report of the committee on the financial aspects of corporate governance. Londres, 1992. Disponível em: <www.jbs.cam.ac.uk/cadbury/report/committee.html>. Acesso em: 19 ago. 2013. 
COHEN, Ernesto; FRANCO, Rolando. Avaliação de projetos sociais. Petrópolis: Vozes, 2007.

CVM. Comissão de Valores Mobiliários. Recomendações da CVM sobre governança corporativa, jun. 2002. Disponível em: <www.cvm.gov.br/port/ public/publ/cartilha/cartilha.doc>. Acesso em: 19 ago. 2013.

DATASUS. Ministério da Saúde. População infantil segundo Região/Unidade da Federação 2010. Disponível em: <http://tabnet.datasus.gov.br/cgi/tabcgi.exe? ibge/censo/cnv/trabinfuf.def> . Acesso em: 27 set. 2013.

DATASUS. Ministério da Saúde. Taxa de analfabetismo por ano segundo Região/Unidade da Federação. Disponível em: <http://tabnet.datasus.gov.br/cgi/ tabcgi.exe?ibge/censo/cnv/alfuf.def> . Acesso em: 20 set. 2013.

FERRAZ JUNIOR, Tércio S. Competência da Anvisa e a regulamentação da propaganda. Revista de Direito Administrativo, v. 251, n. 3, p. 215-232. maio/ago. 2009. Disponível em: < http://bibliotecadigital.fgv.br/ojs/index.php/rda/issue/view/559>. Acesso em: 8 set. 2013.

FERREIRA, Dimas E. S. Experiências recentes de controle social sobre o processo de orçamentação pública municipal no Brasil. Tema: Tributação, orçamentos e sistemas de informação sobre a administração pública. Monografia $2^{\underline{a}}$ colocada no XI Prêmio Tesouro Nacional. Brasília, 2006.

HÖFLING, Eloisa M. Estado e políticas (públicas) sociais. Cadernos Cedes, Campinas, v. 21, n. 55, p. 30-41, nov. 2001.

HOLZER, Marc; KIM, Seang-Tae. Digital governance in municipalities worldwide (2005): a longitudinal assessment of municipal websites throughout the world. Division for Public administration and Development Management, Department of Economic and Social Affairs, United Nations Public Administration Network, 2006. Disponível em: <http://edoc.vifapol.de/opus/volltexte/2009/1151/ pdf/unpan022839.pdf>.

IBGC. Instituto Brasileiro de Governança Corporativa. Código das melhores práticas de governança corporativa. 4. ed. São Paulo: IBGC, 2009.

IBGE. Instituto Brasileiro de Geografia e Estatística. Censo demográfico 2010. Características da população e dos domicílios. Resultados do universo. Disponível em: < http://biblioteca.ibge.gov. br/visualizacao/periodicos/93/cd_2010_caracteristicas_populacao_domicilios.pdf $>$. Acesso em: 12 out. 2013.

IBGE. Instituto Brasileiro de Geografia e Estatística. Perfil dos estados brasileiros. Pesquisa de Informações Básicas Estaduais. Rio de Janeiro, 2013. Disponível em: < http://www.ibge.gov.br/ estadic2012/>. Acesso em: 10 set. 2013.

IBGE. Instituto Brasileiro de Geografia e Estatística. Síntese de indicadores 2010. Pesquisa Nacional por Amostra de Domicílios (Pnad). Rio de Janeiro: IBGE, 2012. Disponível em: < http://biblioteca. ibge.gov.br/visualizacao/livros/liv61566.pdf>. Acesso em: 10 out. 2013. 
IFAC. International Federation Of Accountants. Governance in the public sector: a governing body perspective. PSC, Study 13, 2001. Disponível em: <www.ifac.org/sites/default/files/publications/ files/study-13-governance-in-th.pdf>. Acesso em: 28 ago. 2013.

JANNUZZI, Paulo M. Considerações sobre o uso, mau uso e abuso dos indicadores sociais na formulação e avaliação de políticas públicas municipais. Rev. Adm. Pública, v. 36, n. 1, p. 51-72, jan./ fev. 2002.

JENSEN, Michael. A theory of the firm: governance, residual claims and organizational forms. 1. ed. Cambridge, MA: Harvard University Press, 2001.

KISSLER, Leo; HEIDEMANN, Francisco G. Governança pública: novo modelo regulatório para as relações entre Estado, mercado e sociedade? Rev. Adm. Pública, v. 40, n. 3, p. 479-499, maio/jun. 2006.

LONGO, Francisco. Public governance for results: a conceptual and operational framework. In: THE UNITED NATIONS COMMITTEE OF EXPERTS ON PUBLIC ADMINISTRATION (CEPA) MEETING, $10^{\mathrm{TH}}, 2011$, Nova York.

MANZI, Vanessa A. Compliance no Brasil: consolidação e perspectivas. São Paulo: Saint Paul, 2008. MARTINS, Humberto F.; MARINI, Caio. Um guia de governança para resultados na administração pública. Brasília: Publix, 2010.

MATIAS-PEREIRA, José. Governança no setor público. São Paulo: Atlas, 2010.

OCDE. Organização para Cooperação Econômica e Desenvolvimento. Avaliação da Ocde sobre o sistema e integridade da administração pública federal brasileira, 2011. Disponível em: <www.cgu. gov.br/publicacoes/AvaliacaoIntegridadeBrasileiraOCDE/AvaliacaoIntegridadeBrasileiraOCDE. PDF >. Acesso em: 22 jun. 2013.

OCDE. Organização para Cooperação Econômica e Desenvolvimento. Os princípios da Ocde sobre o governo das sociedades, 2004. Disponível em: <www.oecd.org/daf/ca/corporategovernanceprinciples/33931148.pdf>. Acesso em: 21 ago. 2013.

OCDE. Organização para Cooperação Econômica e Desenvolvimento. The challenge of capacity development: working towards good practice, 2006. Disponível em: <www.oecd.org/development/ governance-development/42389282.pdf>. Acesso em: 28 set. 2014.

OMAN, Charles P.; ARNDT, Christiane. Measuring Governance. OECD Development Centre, Policy Briefs n. 39, OECD, 2010. Disponível em: <www.oecd.org/dev/46123827.pdf>. Acesso em: 8 nov. 2014.

PAES DE PAULA, Ana P. Administração pública brasileira entre o gerencialismo e a gestão social. Revista de Administração de Empresas, v. 45, n. 1, p. 36-49, jan./mar. 2005.

PINHO, José A. G.; SACRAMENTO, Ana R. S. Accountability, já podemos traduzi-la para o português? Rev. Adm. Pública, v. 43, n. 6, p. 1343-1368, 2009. 
PLATT NETO, Orion A. et al. Publicidade e transparência das contas públicas: obrigatoriedade e abrangência desses princípios na administração pública brasileira. Contabilidade Vista \& Revista, Belo Horizonte, v. 18, n. 1, p. 75-94, jan./mar. 2007.

PNUD. Programa das Nações Unidas para o Desenvolvimento. Atlas do desenvolvimento humano do Brasil 2013. O índice de desenvolvimento humano municipal. Disponível em: <www.pnud.org.br /atlas/ranking/Ranking-IDHM-UF-2010.aspx>. Acesso em: 8 out. 2013.

SOUZA, Thelma M. G. Governança corporativa e o conflito de interesses nas sociedades anônimas. São Paulo: Atlas, 2005.

SPINK, Peter K. Processos organizativos e ação pública: as possibilidades emancipatórias do lugar. In: JACÓ-VILELA, Ana M.; SATO, Leny (Org.). Diálogos em psicologia social [online]. Rio de Janeiro: Centro Edelstein de Pesquisas Sociais, 2012. p. 352-369.

TELLES, Vera. Medindo coisas, produzindo fatos, construindo realidades sociais. In: SEMINÁRIO INTERNACIONAL SOBRE INDICADORES SOCIAIS PARA INCLUSÃO SOCIAL. Núcleo de Estudos e Pesquisas em Seguridade e Assistência Social do Programa de Estudos Pós-Graduados da PUC-SP, 15-16 maio 2003, São Paulo. Disponível em: <www.dhnet.org.br/direitos/indicadores/sistema_br/ novib_mat06.pdf>. Acesso em: 9 out. 2013.

TRIBUNAL DE CONTAS DA UNIÃO (TCU). Contas. Disponível em: < http://portal2.tcu.gov.br/ portal/page/portal/TCU/comunidades/contas/contas_governo/>. Acesso em: 30 ago. 2013.

TRIBUNAL DE CONTAS DA UNIÃO (TCU). Normas de auditoria do Tribunal de Contas da União. Revisão junho 2011. Boletim do Tribunal de Contas da União, especial, ano XLIV, n. 12. Brasília: TCU, 2011. Disponível em: < http://portal2.tcu.gov.br/portal/page/portal/TCU/comunidades/ fiscalizacao_controle/normas_auditoria/BTCU-ESPECIAL-12-de-05-072011\%20Normas\%20de\%20 Auditoria.pdf > . Acesso em: $\overline{30}$ ago. 2013.

TRIBUNAL SUPERIOR ELEITORAL. Estatísticas e resultados da eleição. Disponível em: <www.tse. jus.br/eleicoes/eleicoes-anteriores/eleicoes-2010/estatisticas>. Acesso em: 12 out. 2013.

VAN DE WALLE, Steven. Measuring bureaucratic quality in governance indicators. In: EGPA ANNUAL CONFERENCE, STUDY GROUP ON PRODUCTIVITY AND QUALITY IN THE PUBLIC SECTOR, 2005, Bern. Leuven: Instituut voor de Overheid, 2005.

Antonio Gonçalves de Oliveira é doutor em engenharia de produção pela Universidade Federal de Santa Catarina (UFSC), professor do Departamento Acadêmico de Gestão e Economia da Universidade Tecnológica Federal do Paraná (Dagee/UTFPR), coordenador e professor do Programa de Pós-Graduação em Planejamento e Governança Pública (PPGPGP/UTFPR), professor do Programa de Pós-Graduação em Administração (PPGA/UTFPR), líder do grupo de pesquisa em Gestão Pública e Desenvolvimento. E-mail: agoliveira@utfpr.edu.br.

Beatriz Jackiu Pisa é mestre em planejamento e governança pública e pesquisadora do grupo de pesquisa em Gestão Pública e Desenvolvimento da Universidade Tecnológica Federal do Paraná (UTFPR). Ocupa a função de coordenadora de Filial na Caixa Econômica Federal. E-mail: bia_pisa@yahoo.com.br. 


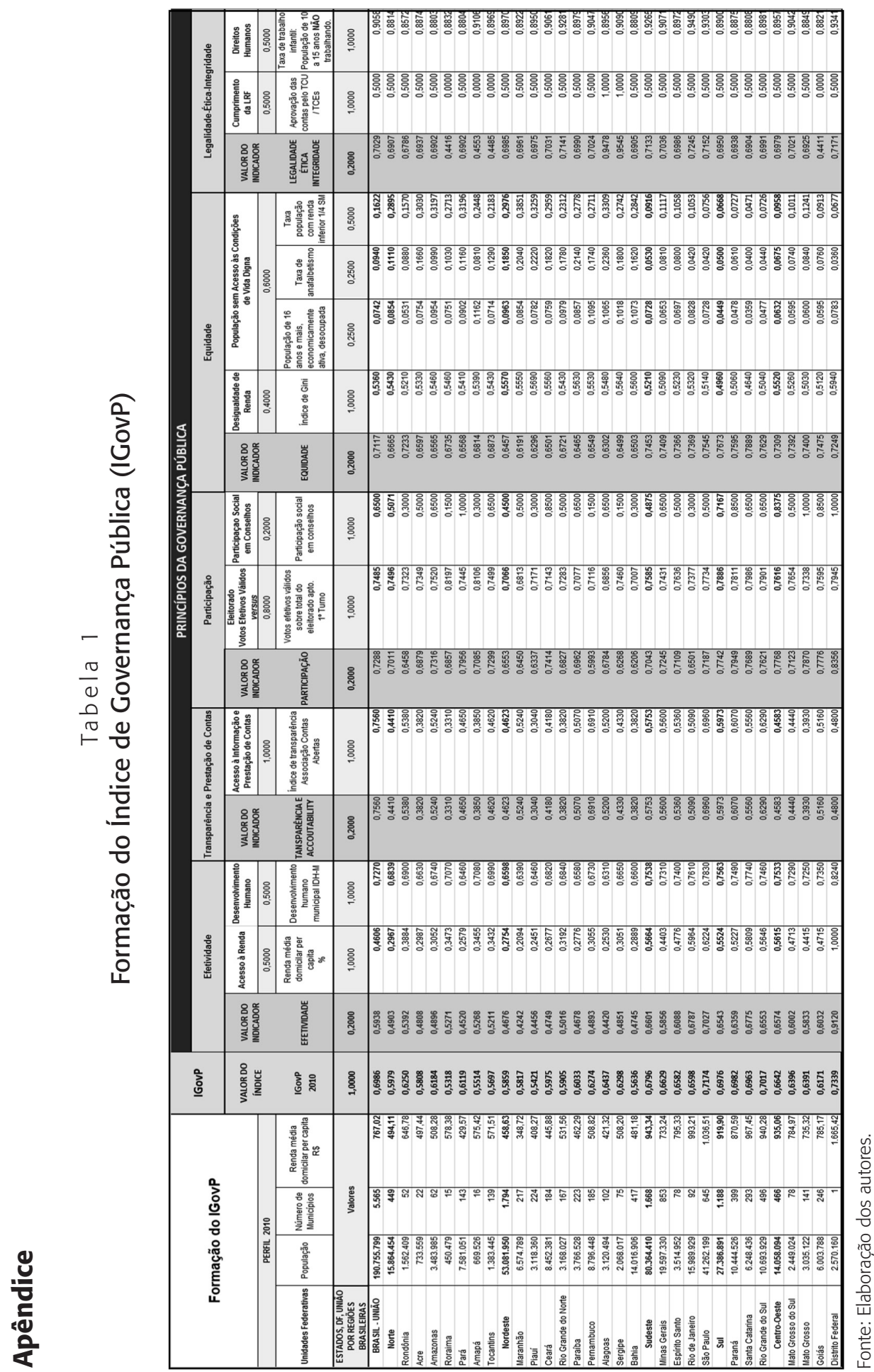

Rev. Adm. Pública - Rio de Janeiro 49(5):1263-1290, set./out. 2015 